\title{
Research on elastic-plastic failure behavior of steel double-layer grids structure system (36X36 m)used in the badminton practice gymnasium under strong earthquake wave
}

\author{
Jiajia WANG ${ }^{1, a}$, Haiwang $\mathrm{LI}^{1, b^{\star}}$, and Jing LIU $^{1, c}$ \\ ${ }^{1}$ Department of Civil Engineering, Taiyuan University of Technology, \\ 79, Yingzexi Street, Taiyuan, 030024, China \\ awangjia19860225@126.com, ' Ihwtut@126.com (corresponding author), \\ ccimeng2005@163.com
}

\begin{abstract}
Keywords: Strong earthquake, Nonlinear, Time history analysis, Plastic hinge, Failure, Seismic performance
\end{abstract}

\begin{abstract}
In this paper, the analysis on dynamic failure behaviors of steel double-layer grids supported by circumjacent steel columns used in a gymnasium with the function of earthquake victims shelter under strong earthquake wave is carried out under EL-Centro wave with SAP2000, and the appraisal results on their anti-failure performances are presented based on the plastic-hinge theory. In the analysis, the geometric and material nonlinear effects are considered simultaneously. The plastic development level of the rods, the deformed shape and the failure type and the ductility are estimated by plastic hinge principle. The results show that the failure model of the structure under the earthquake wave action is the complicated combination of strength failure and elastic-plastic dynamic local buckling in deferent areas of the structure; When the structure reached its failure critical limit, the development of the plastic hinges is not sufficient and only $9.95 \%$ of the rods enter into their plastic stage; Its critical failure peak acceleration of EL earthquake wave when applied in the combination of two directions is 1499.1 gal, which is 3.75 times more than the official seismic fortification level of 8 degree (major earthquake, $0.4 \mathrm{~g}$ ) and can be served as earthquake victims shelter in the area of 8 degree seismic fortification; Its displacement ductility coefficient is 5.585 , which shows the structure owns good energy dissipation capacity.
\end{abstract}

\section{Introduction}

Double-layer grids with their structural advantages and good seismic performance are widely used in large span buildings in China. Previous recent disastrous earthquakes show that the large span public buildings were used as earthquake shelters and disaster relief headquarter sites ${ }^{[1]}$. So the large span public buildings newly designed are gradually required to have the function of earthquake shelters. In order to work safely during disastrous earthquakes, the structures of these buildings are required to be designed under strong earthquake action larger than the official seismic major fortification earthquake level. Therefore the appraisal method on their anti-collapse performances under strong earthquake action is needed to be studied. In this paper, the elastic-plastic dynamic analysis on dynamic failure behaviors of steel double-layer grids in a gymnasium with the function of earthquake victims shelter under disaster earthquake is carried out and appraisal results on their anti-failure performances are presented under strong earthquake action based on the plastic-hinge theory ${ }^{[2]}$.

\section{Analysis Model}

A badminton practice gymnasium with plane size of 36X36 m and cornice elevation level of 12 $\mathrm{m}$ is shown in Fig.1. 


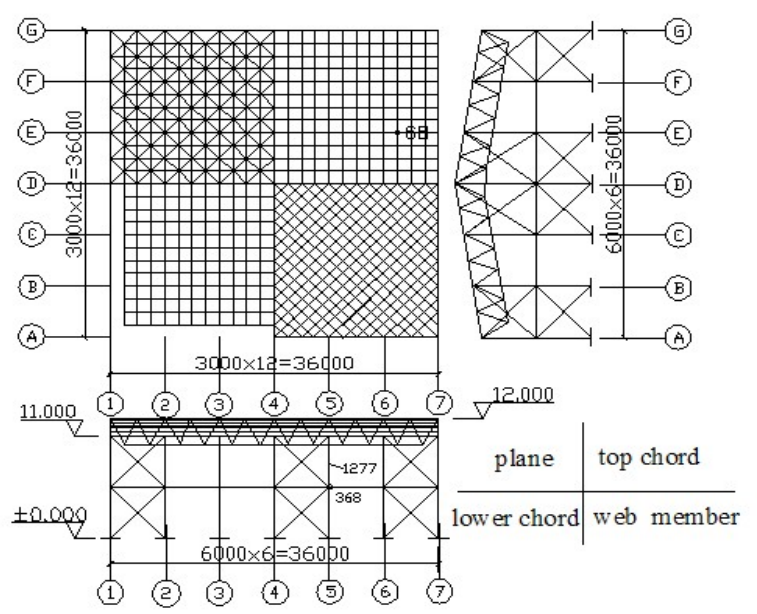

Fig. 1 Structure layout

(The number and the signs those shown in this figure are feature nodes)

Its roof structure is a double-layer grid with square on square pyramids supported by circumjacent steel columns. Its grid size is $3 \mathrm{~m} \mathrm{X3m}$, its grid height is $2.4 \mathrm{~m}$. The gymnasium structure is designed firstly according to the current national standards ${ }^{[3]}$ with official seismic fortification level of 8 degree $(0.4 \mathrm{~g})$ and site classification of type III, design reference period of 50 years, design characteristic period of ground motion of $0.45 \mathrm{~s}$. Its peak ground acceleration for the small and the major earthquake is respectively 70 gal and 400 gal $^{[4]}$. The damp is taken as Rayleigh with the damping ratio 0 f 0.02 or 0.05 for elasticity or elastic-plasticity. The material adopts bilinear elastic-plastic material model with the density $7850 \mathrm{Kg} / \mathrm{m} 3$, elasticity modulus $2.06 \mathrm{Gpa}$, tangent modulus $6.18 \mathrm{GPa}$, the Poisson ratio 0.3 , and the yield strength $235 \mathrm{MPa}$. The top chord cross section sizes are among $\phi 76 \mathrm{X} 4, \phi 114 \mathrm{X} 6, \phi 127 \mathrm{X} 6$ and $\phi 180 \mathrm{X} 6$, the lower chord cross section sizes are among $\phi 76 \mathrm{X} 4$, $\phi 114 \mathrm{X} 6, \phi 127 \mathrm{X} 6$ and $\phi 180 \mathrm{X} 6$, the web member cross section sizes are $\phi 76 \mathrm{X} 4, \phi$ 127X6,Column H 400X400X21X21, and the cross section sizes used in circumjacent steel columns are $\varphi 127 \mathrm{X} 6$ and $\varphi 102 \mathrm{X} 4$. The nonlinear analysis on the spatial truss under EL-Centro wave is carried out with plastic hinge method by SAP2000. The generalized force-displacement relation for the plastic hinge defined in the members of the structure is defined according to FEMA356 $6^{[5]}$.

\section{Results and Analysis}

Nonlinear time history calculations on the model are carried out by SAP2000 with El-Centro wave chosen as earthquake wave applied in the combine direction of $\mathrm{X}+0.65 \mathrm{Z}$. The initial condition for each time-history calculation is the deformed state of the structure under the whole dead load and the half snow load. Many calculations with different peak value of the input earthquake wave applied to the structure designed according to the official Seismic fortification level(shorted as SFL) are carried out to find two limit conditions for the structure. The first is the elastic limitation; the second is critical failure state. The failure model is shown in Fig.2 5. The maximum displacement response of the structure in the horizontal and vertical direction, the relationship curves between the maximum displacement of nodes and peak ground acceleration (shorted as PGA) are respectively shown in Tab.1, Fig.6 8. Displacement ductility coefficients of the structure are listed in Tab. 2. The number and the distribution of the plastic hinge are provided in Tab.3.

According to Tab.1 3 and Fig.2 8, the results can be concluded as follows:

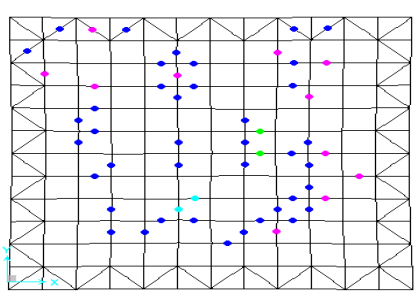

Fig. 2 top chord's plastic hinge

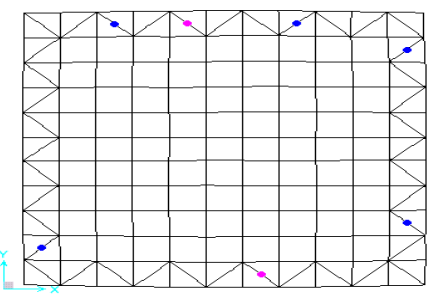

Fig. 3 lower chord's plastic hinge 


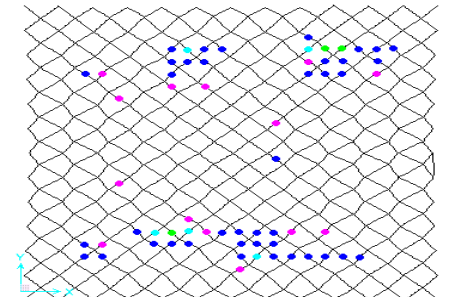

Fig. 4 web member's plastic hinge

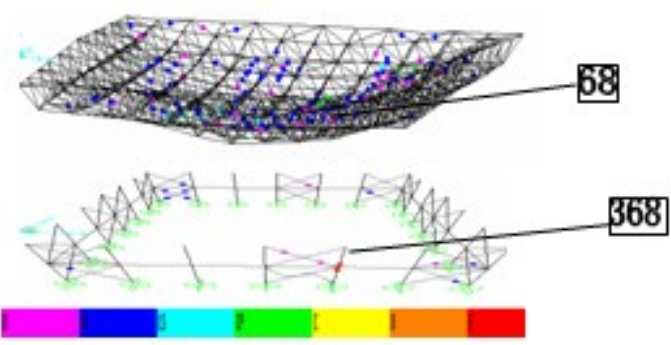

Fig.5 The failure mode and the plastic hinge distribution

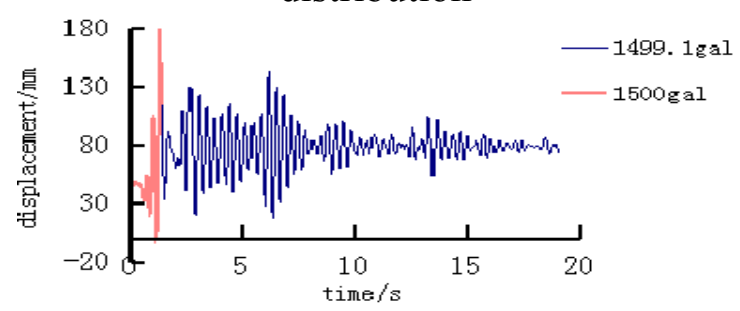

Fig.6 The vertical displacement of the node 68 - schedule curve

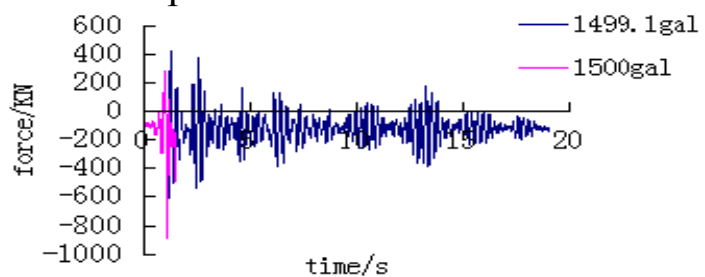

Fig.7 The frame column 1277 unit axial force-schedule curve

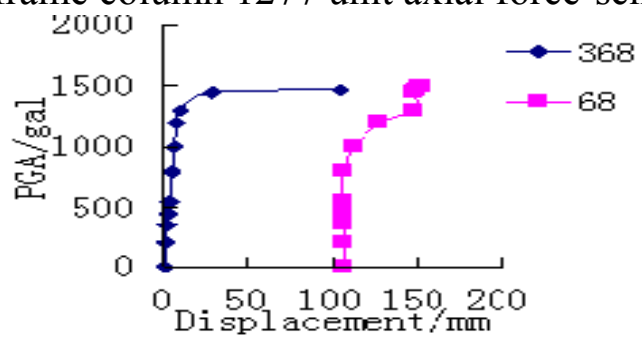

Fig. 8 The vertical displacement of the node 68 and the horizontal displacement of the feature node 368 - PGA curve

The elastic limitation PGA for two directions input is 421. It is much larger than the PGA of the official SEL for small earthquake (70gal).

According to the B-R criterion ${ }^{[6,7]}$, the failure model of the structure under the earthquake wave action is the complicated combination of strength failure and elastic-plastic dynamic local buckling in deferent areas of the structure. The critical PGA for this direction input is 1499.1gal. It is much larger than the PGA of the official SEL for major earthquake (400gal).

The displacement ductility coefficient is 5.585 and the ratio of its bars with plastic hinge appearing for ultimate critical state is only $9.95 \%$ when EL earthquake waves applied on the structure, the development of the plastic hinges is not sufficient.

When its critical failure peak acceleration of EL earthquake wave when applied in the combination of two directions, all the members in the E stage are compression failure.

All results about show the structure have some deformed capacity and energy-dissipation capacity before collapse under earthquake.

Tab.1 Critical PGA for two limitations

\begin{tabular}{|c|c|c|c|c|c|c|c|c|}
\hline \multirow{2}{*}{$\begin{array}{c}\text { Feature } \\
\text { Nodes }\end{array}$} & $\begin{array}{c}\text { Displacement } \\
{[\mathrm{mm}]}\end{array}$ & \multicolumn{6}{|c|}{ Critical PGA [gal] } & $1499.1 \mathrm{gal}$ \\
\cline { 3 - 9 } & $\Delta 21$ & 1000 & 1300 & 1450 & 1499.1 & 1500 & $\begin{array}{c}\Delta 1 / \mathrm{H} \\
{[\Delta 2 / \mathrm{L}]}\end{array}$ \\
\hline 68 & $\Delta 1$ & 106.8 & 112.5 & 127.28 & 139.09 & 152.2 & - & $1 / 237$ \\
\hline 368 & $\Delta 2$ & 5.11 & 6.05 & 9.52 & 107.73 & 592.03 & - & $1 / 61$ \\
\hline
\end{tabular}

Note: $\Delta 1 / \Delta 2$ is the spatial displacement; "- " indicates that this structure has destroyed under the given 
acceleration; $\mathrm{H}$ is the height of the column.L is the shorter roof span; $\mathrm{L}$ is the shorter roof span.

Tab. 2 Displacement ductility coefficients

\begin{tabular}{|c|c|c|c|}
\hline Critical PGA [gal] & Node number & Absolute displacement & yield Displacement ratio \\
\hline 421 & 68 & 106 & 1.000 \\
\hline 1499.1 & 368 & 592 & 5.585 \\
\hline
\end{tabular}

Tab.3 The plasticity development level in 1499.1gal

\begin{tabular}{|c|c|c|c|c|c|c|}
\hline \multirow{2}{*}{$\begin{array}{c}\text { Rod } \\
\text { categories }\end{array}$} & \multicolumn{4}{|c|}{ Number and percentage of plastic hinges[\%] } & \multirow{2}{*}{$\begin{array}{c}\text { Total percentage } \\
{[\%]}\end{array}$} \\
\cline { 2 - 6 } & B-IO & IO-LS & LS-CP & CP-C & C-E & 4.2 \\
\hline Top chord & $11(3.3)$ & $40(12.1)$ & $2(0.6)$ & $2(0.6)$ & $1(0.3)$ & 0.5 \\
\hline Lower chord & $2(0.6)$ & $5(1.6)$ & - & - & - & 4.44 \\
\hline Web member & $15(2.6)$ & $39(6.67)$ & $6(1.04)$ & $2(0.3)$ & - & - \\
\hline (1) axis Column & - & - & - & - & - & - \\
\hline (7) axis Column & - & - & - & - & - & 0.5 \\
\hline A axis Column & $3(1.63)$ & $2(1.09)$ & - & - & $2(1.09)$ & 0.5 \\
\hline G axis Column & $1(0.54)$ & $6(3.26)$ & - & - & - & - \\
\hline
\end{tabular}

Note: “-” indicates that no plastic hinge; The value in the brackets means the percentage of the rods with plastic hinge in all rods.

\section{Conclusion}

Because of the structure's uncertainty and diversity, to establish the reasonable physical model and find the right mathematical tools to describe the system to simulate the whole process collapsed structure is still a difficult one. With the development of the theory and experiment, on the dynamic elastic-plastic failure analysis methods and detailed tests will be closer to true behavior, which can provide better methods based on the analysis for continuous collapsed.

\section{Acknowledgements}

This project is financially supported by National Natural Science Foundation of China (50878137); Key Project Foundation of Shan xi Province (20080321086) and Shan xi Province Foundation for Scholar Returned From Abroad (2009-26).

\section{References}

[1] H.W. Li, H.S. Zhao, Y.J. Zhao: Study on Planning for the Indoor-earth quake- shelter in City and Town. (Advanced Science Letters), USA, 2011, Vol. 4, pp. 2654-2665.

[2] Civil King Software Technology Co., Ltd. China institute of Building Standard Design \& Research. Usage Guide to Structure Analysis Program SAP2000 Chinese Edition [CP] (China communications press, China, 2006), p.460.

[3] JGJ7-91(1991 edition) Code for grid structure design and construction [S]. (China architecture \& building press, Beijing, 1991)

[4] GB50011-2010(2010 edition) Code for seismic design of buildings[S]. (China architecture \& building press, Beijing, 2010).

[5] FEM 356 the Seismic Rehabilitation of Buildings[S]. Federal Emergency Management Agency, 2000.

[6] S.S. Zhao and C. Xin: Dynamic stability of grid structure[M] (Beijing, Science Press, 1999).

[7] H.W. Li, J.X. Li, F. Zhi, F. Ma and D.Q. Qin: Proceedings of the 6th International Conference on Computation of Shell and Spatial Structures IASS-IACM (Cornell University, Ithaca, NY, USA, May 28-31, 2008). 